\title{
Study on progression of deterioration in improved surplus soils
}

\author{
Dayani Sanjeewani ${ }^{1, *}$, Yukika Miyashita ${ }^{2}$, Reiko Kuwano ${ }^{1}$, and Atsunori Negishi ${ }^{3}$ \\ ${ }^{1}$ Institute of Industrial Science, The University of Tokyo, 4-6-1 Komaba, Meguro-ku, Tokyo, Japan \\ ${ }^{2}$ Public Works Research Institute, 1-6 Minamihara, Tsukuba, Ibaraki, Japan \\ ${ }^{3}$ Hanzama Ando corporation, 515-1 Karima, Tsukuba, Ibaraki, Japan
}

\begin{abstract}
This study investigated the progression of deterioration in cement treated surplus soils with cement contents of 1.7, 3.5 and $5.3 \%$ under soaked condition by conducting needle penetration test and measuring calcium ion distribution within soil specimens. It was found that deterioration has progressed throughout the specimen after 336 days soaking in all the cases. From the measurement of calcium ion distribution, it was identified that calcium has leached out from the centre to the surface of the specimens though that distribution did not follow a good correlation with localized strength distribution. It was understood that the progression of deterioration of improved surplus soils with lower cement contents cannot be explained only with the remaining amount of calcium.
\end{abstract}

\section{Introduction}

In Japan, re-utilization of surplus soils (construction generated soils) in earthworks is highly promoted and increases year by year. One of the ways to use low-quality surplus soil is to improve them by applying chemical stabilization using cement and utilize them as a filling or embankment material in road embankments. The durability and stability of such road embankments are affected by the change of the long-term mechanical properties of the improved soils by subjecting to different environmental exposure conditions. Various laboratory/field studies have been conducted on the deterioration of cement treated soil [1-4] in which needle penetration resistance of treated soils was measured. Most of the above studies were based on deep mixing technique under exposure of sea water. In those studies, dissolution of calcium was observed as one of the major causes in strength reduction.

Generally, the improved soils used in road embankments are lower in cement contents than deep mixing improvement. In such a case, those embankments are susceptible to the penetration of rain water or ground water [5]. Authors conducted a series of unconfined compression tests on improved soil with lower cement contents and reduction in unconfined compressive strength was observed under soaked condition [6]. In addition to that, it was observed continuous leaching of calcium ions from specimen to soaking water. However, the progression of deterioration on those improved surplus soils with low mixing ratios are not well understood yet.

In this study, therefore, the effect of soaking on localized strengths was studied by conducting needle penetration tests after improving the poor-quality surplus soil with lower mixing ratios of cement. An effort was taken to explain the progression of deterioration by using localized strengths and calcium ion distribution within the soil specimen.

\section{Experimental procedure}

\subsection{Material}

An actual surplus soil called Miho sand was used, in this study. Physical and mechanical properties of Miho sand are shown in Table 1. A hexavalent chromium soluble cement-based product (called hereafter as cement) was used as the binder. Chemical properties of Miho sand and the cement are tabulated in Table 2. The amounts of cement were set to $1.7,3.5$ and $5.3 \%$ by dry weight of natural soil. The middle amount of cement was set by considering the 7 days unconfined compressive strength as of $100 \mathrm{kN} / \mathrm{m}^{2}$. It coincides with the minimum value which is empirically recommended in the manual [7]. The smaller amount and larger amount were simply set to be as 0.5 times and 1.5 times of the middle amount to investigate the effect of the cement content.

Table 1. Physical and mechanical properties of Miho sand

\begin{tabular}{|l|c|}
\hline Soil classification (JGS 0051) & SF (sandy soil) \\
\hline Soil particle density, $\rho_{\mathrm{s}}\left(\mathrm{g} / \mathrm{cm}^{3}\right)$ & 2.693 \\
\hline Optimum water content, $\mathrm{w}_{\mathrm{opt}}(\%)$ & 21.6 \\
\hline Maximum dry density, $\rho_{\mathrm{dmax}}\left(\mathrm{g} / \mathrm{cm}^{3}\right)$ & 1.624 \\
\hline Sand $(\%)$ & 52.9 \\
\hline Silt $(\%)$ & 21.6 \\
\hline Clay $(\%)$ & 24.7 \\
\hline
\end{tabular}

\footnotetext{
* Corresponding author: dayani@iiis.u-tokyo.ac.jp
} 
Table 2. Chemical properties of Miho sand and cement

\begin{tabular}{|c|c|c|c|c|c|c|c|c|c|c|c|c|}
\hline & $\begin{array}{c}\mathrm{SiO}_{2} \\
(\text { wt \%) }\end{array}$ & $\begin{array}{c}\mathrm{TiO}_{2} \\
(\text { wt \%) }\end{array}$ & $\begin{array}{l}\mathrm{Al}_{2} \mathrm{O}_{3} \\
(\text { wt } \%)\end{array}$ & $\begin{array}{l}\mathrm{Fe}_{2} \mathrm{O}_{3} \\
(\mathrm{wt} \%)\end{array}$ & $\begin{array}{c}\mathrm{MnO} \\
(\text { wt } \%)\end{array}$ & $\begin{array}{c}\mathrm{MgO} \\
(\text { wt \%) }\end{array}$ & $\begin{array}{c}\mathrm{CaO} \\
(\mathrm{wt} \%)\end{array}$ & $\begin{array}{c}\mathrm{Na}_{2} \mathrm{O} \\
(\text { wt } \%)\end{array}$ & $\begin{array}{c}\mathrm{K}_{2} \mathrm{O} \\
(\mathrm{wt} \%)\end{array}$ & $\begin{array}{c}\mathrm{P}_{2} \mathrm{O}_{5} \\
(\mathrm{wt} \%)\end{array}$ & $\begin{array}{c}\text { Stotal } \\
(\text { wt \%) }\end{array}$ & $\begin{array}{c}\mathrm{SO}_{3} \\
(\mathrm{wt} \%)\end{array}$ \\
\hline Miho sand & 61.69 & 0.73 & 19.92 & 6.86 & 0.11 & 1.29 & 1.48 & 1.18 & 1.54 & 0.10 & 0.03 & - \\
\hline Cement & \multicolumn{6}{|c|}{ Not measured } & 56.37 & \multicolumn{3}{|c|}{ Not measured } & 3.13 & 6.08 \\
\hline
\end{tabular}

The water content of the Miho sand was set to $31 \%$. Cement and Miho sand were mixed uniformly by a soil mixer around 5 minutes. The specimens $50 \mathrm{~mm}$ in diameter and $100 \mathrm{~mm}$ in height were prepared by applying static compaction. The degree of compaction of each specimen was set to $1.4 \mathrm{~g} / \mathrm{cm}^{3}$ by refering to the result of a compaction experiment performed using an actual construction machine.

\subsection{Curing method}

All specimens were cured and tested under two different curing conditions as schematically shown in Fig. 1. In case 1 which is called hereafter as sealed, one set of specimens were wrapped with plastic wrapping and cured under constant temperature. Then saturation was applied under pure water by applying vacuum pressure 1 day priority to the corresponding curing date. To evaluate the effect of soaking on the strength, the second set of specimens were cured under artificially made acidic water as in case 2 . The $\mathrm{pH}$ value of the acidic water was set to 4.5 by mixing pure water with sulfuric acid $\left(\mathrm{H}_{2} \mathrm{SO}_{4}\right)$, nitric acid $\left(\mathrm{HNO}_{3}\right)$ and hydrochloric acid $(\mathrm{HCl})$ by 5:2:3 proportionally to simulate the actual acid rain in Japan. The volume ratio of a specimen and the acidic water was set to 1:5. Specimens were started to be soaked three days after their preparation. In the first 28 days, acidic water was exchanged once a week, then the duration of the exchange was increased to two weeks until 168 days and finally to 4 weeks after 168 days.
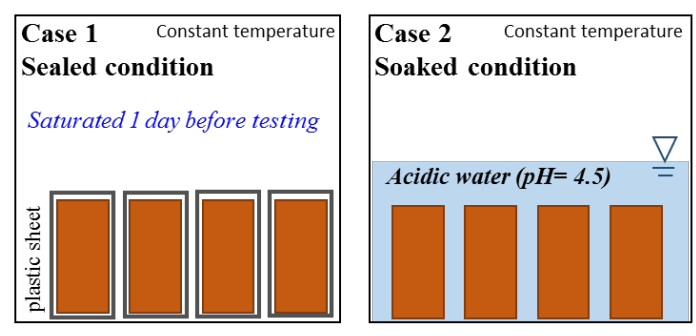

Fig. 1. Curing conditions

\subsection{Mechanical and chemical testing procedure}

Needle penetration tests (JGS 3431) were conducted on the all two sets of specimens after 7, 28, 168 and 336 days from their preparation. The needle size was $0.84 \mathrm{~mm}$ in diameter and $30 \mathrm{~mm}$ in length. The needle was penetrated with a penetration speed of $11 \mathrm{~mm} / \mathrm{min}$ from three directions at the middle height of the specimen as illustrated in Fig. 2. Penetration resistance was measured by using a load cell and an electric balance.

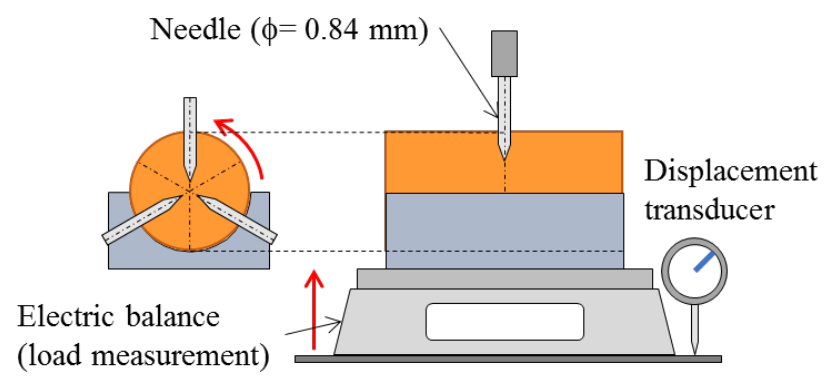

Fig. 2. Outline of specimen set up in needle penetration test

To evaluate the calcium content of the specimens, analysis by X-ray Fluorescence spectrometer (called hereafter as XRF) was conducted on the powdered soil samples at curing periods of 28, 168 and 336 days. In all curing periods, soil samples were collected from the sealed and soaked specimens at distance as of 0-5 $\mathrm{mm}$ and 20-25 $\mathrm{mm}$ from the surface. Additional soil samples were collected from an intermediate distance of 10-15 mm and outer most surface $(0 \mathrm{~mm})$ only after 336 days curing as schematically shown in Fig. 6 (a).

Electron probe micro analyzer (EPMA) was applied on cross sections which were sliced at the middle height of the cement $3.5 \%$ specimens after curing of 28,168 and 336 days to confirm the distribution of $\mathrm{Ca}^{2+}$. Before applying EPMA, the specimen was reinforced by the intrusion of an epoxy resin. In order to prevent losing of water-soluble minerals, the surface was polished using kerosene until gaining a smooth surface. Finally, the specimen was dried under vacuum and applied a carbon coating. EPMA measurement was taken with an acceleration voltage of $50 \mathrm{kV}$, beam current of $100 \mathrm{nA}$, unit measurement time of $10 \mathrm{~ms} /$ point and pixel size of 35 $\mu \mathrm{m}$. Ion distribution of calcium, carbon, and silica were obtained.

\section{Results and discussion}

\subsection{Influence of exposure condition on localized strength}

The relationships between needle penetration resistance (NPR) and the penetration length under sealed and soaked conditions were summarized according to the cement contents as shown in Figs. 3 and 4, respectively. It should be noted that the horizontal axis of Fig. 3 (c) and Fig. 4 (c) are three times larger than the others.

Under the sealed condition, maximum values of NPR in cement contents of 3.5 and $5.3 \%$ became large when increasing the curing from 7 to 336 days, while those values of $1.7 \%$ did not show significant change.

\footnotetext{
${ }^{*}$ Corresponding author: dayani@,iis.u-tokyo.ac.jp
} 


\section{Penetration resisatce, $\mathrm{P}(\mathrm{N})$}

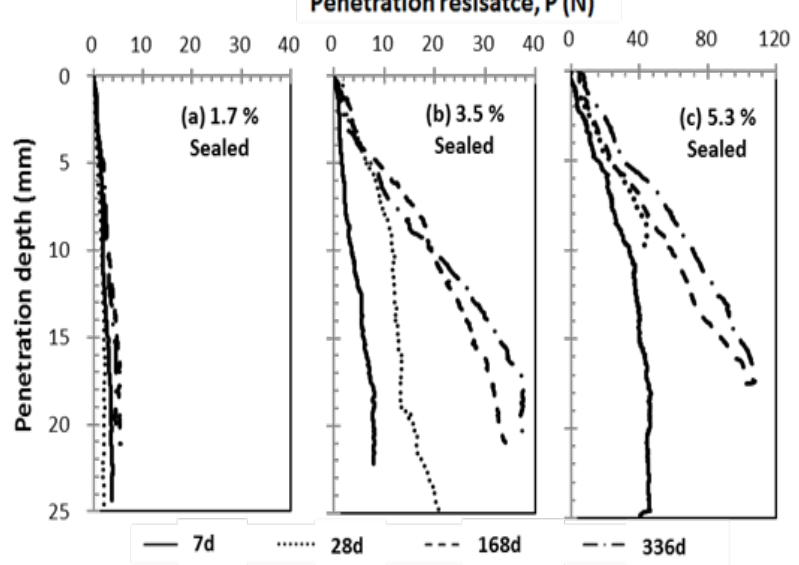

Fig. 3. Needle penetration test results in different curing period-Sealed condition

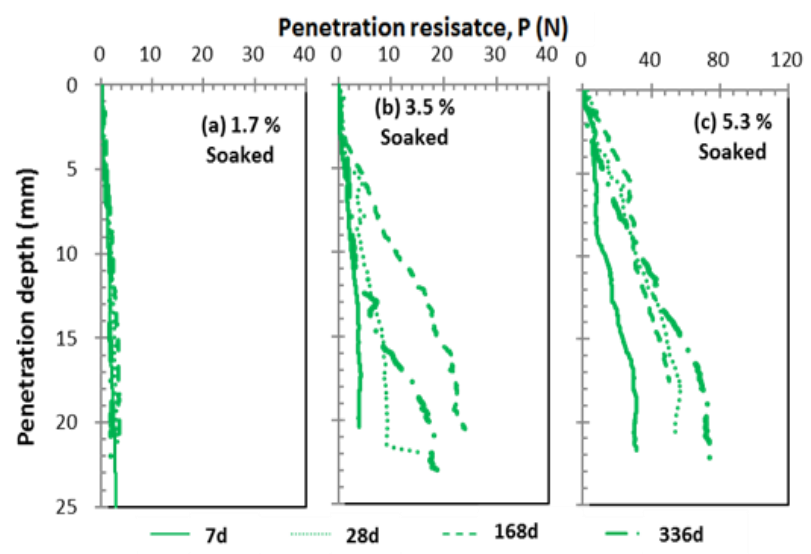

Fig. 4. Needle penetration test results in different curing period- Soaked condition

Under the soaked condition, NPRs in both cement contents of 3.5 and $5.3 \%$ were increased while increasing curing period from 7 to 168 days. After the curing of 336 days, NPR of cement $3.5 \%$ was smaller than NPR of 168 days in all depths. Especially, a very small NPR was observed at a depth less than $10 \mathrm{~mm}$. In the case of cement $5.3 \%$, NPR after curing of 336 days was smaller than 168 days only at a depth less than $10 \mathrm{~mm}$ while the strength in the core (depth $>10 \mathrm{~mm}$ ) was increased. NPR of cement content $1.7 \%$ did not show any trend with the curing period.

When comparing the NPRs of sealed and soaked curing, NPRs of soaked specimens at arbitrary depths were lower than those of sealed specimens at 28, 168 and 336 days in all cement contents. Similar observations were made in the other two horizontal measurements also. These results proved that reduction of strength relative to sealed curing (called here after as deterioration) of improved surplus soil occurred due to soaking. This might be due to the changes in chemical properties of the soaked specimens result in dissolution of calcium [6].

\subsection{Progression of deterioration in soaked specimens}

Deterioration of the soaked specimens was evaluated as a penetration resistance ratio [3], $\mathrm{R}_{\mathrm{p}}$, at an arbitrary depth from the exposed surface. $R_{p}$ is defined as the ratio of NPR of the soaked specimen to the average value of three measurements of sealed specimens at a particular depth. It was evaluated at four depths as 2, 5, 10, $20 \mathrm{~mm}$ from the exposed surface. In the case of cement $5.3 \%, \mathrm{R}_{\mathrm{p}}$ has evaluated only up to $10 \mathrm{~mm}$ depth due to lack of measurements under the sealed condition. Fig. 5 (a), (b) and (c) show the relationships between $R_{p}$ and the curing period of cement contents $1.7,3.5$ and $5.3 \%$, respectively. The variation of three measurements obtained in needle penetration test at a particular curing age is shown by the vertical line "I".
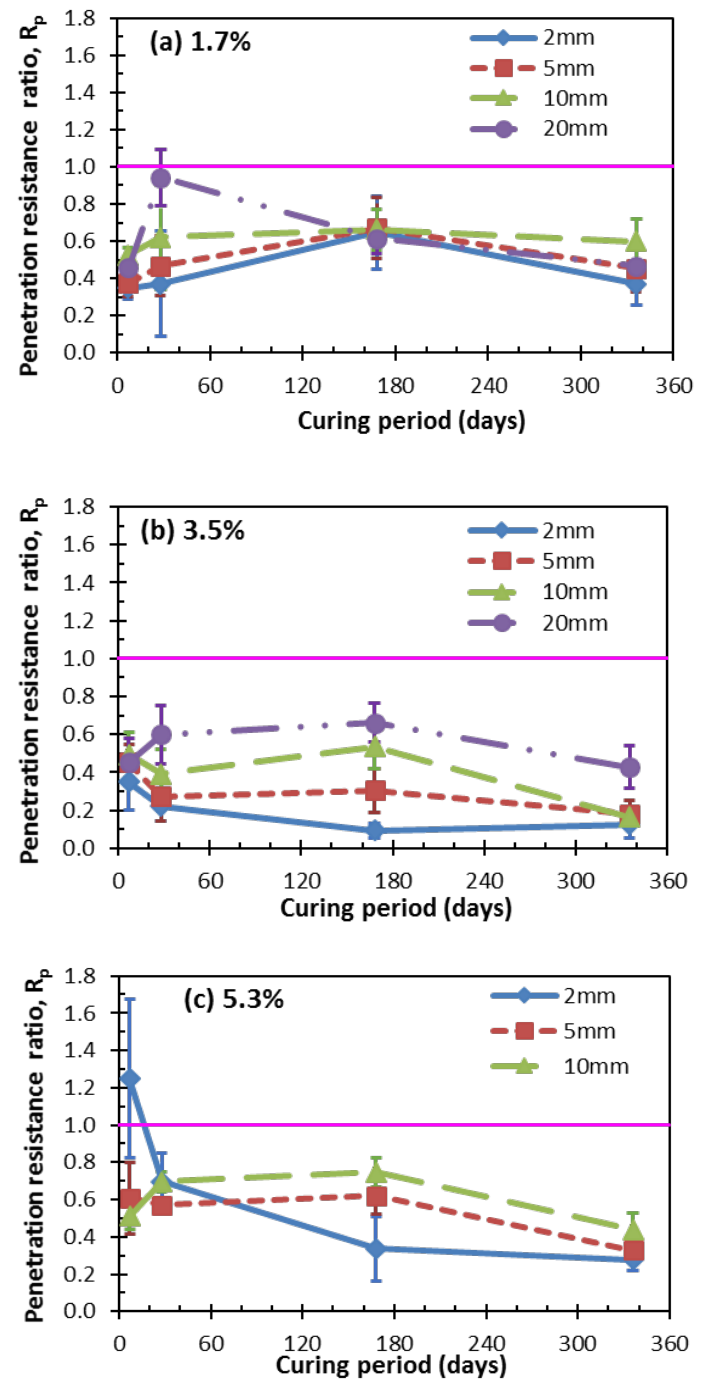

Fig. 5. Relationships between penetration resistance ratio, $\mathrm{R}_{\mathrm{p}}$ and curing period

$\mathrm{R}_{\mathrm{p}}$ of all soaked specimens was less than 1.0 irrespective to the depths and the curing periods. In cement contents of 3.5 and $5.3 \%$, this proved that deterioration has progressed throughout the specimens. This behaviour was different from the observations of previous studies $[1,2]$ with larger cement contents under 
soaking of sea water. In those studies, reduction in strengths was found only at the surface but not to the core area. Therefore, comparing with the larger cement contents, soil improved with lower mixing ratios can suffer a larger reduction in strength under soaking which might need more attention in large scale structures such as road embankments.

In cement contents of 3.5 and $5.3 \%, \mathrm{R}_{\mathrm{p}}$ value at the depth of $10 \mathrm{~mm}$ clearly reduced while increasing curing period from 168 to 336 days. These results showed that further deterioration was progressed in to deeper of the cement 3.5 and $5.3 \%$ specimens. Especially in cement $3.5 \%, \mathrm{R}_{\mathrm{p}}$ at $2 \mathrm{~mm}$ depth showed the approximate value of 0.1 in both curings of 168 and 336 days. By considering the above fact, a new term called "degraded depth" was introduced when $\mathrm{R}_{\mathrm{p}}$ was less than 0.1 to quantify the depth where extreme deterioration occurred. According to that concept, cement $3.5 \%$ specimen had a $2 \mathrm{~mm}$ degraded depth after 336 days of soaking.

In the case of cement $1.7 \%$, it was difficult to evaluate accurately the reason to have $R_{p}$, less than 1 whether it was due to the difference in physical properties of the specimen or not [6].

\subsection{Variation of calcium content with soaking period}

Fig.6 (b) shows the relationship between $\mathrm{Ca}^{2+}$ weight percentage and the distance from the surface of sealed and soaked specimens after curing for 336 days. $\mathrm{Ca}^{2+}$ percentage of Miho sand also is shown in the same figure. $\mathrm{Ca}^{2+}$ percentage was calculated from $\mathrm{CaO}$ percentage obtained by XRF analysis. It should be noted that $\mathrm{Ca}^{2+}$ percentage showed in each case represented total $\mathrm{Ca}^{2+}$ from both Miho sand and cement. Under sealed condition, $\mathrm{Ca}^{2+}$ percentages in all the specimens did not change with the distance. On the other hand, under soaked condition $\mathrm{Ca}^{2+}$ had leached out from centre to surface. A noticeable reduction was observed at the distance less than $5 \mathrm{~mm}$ from the exposed surface in cement 3.5 and $5.3 \%$. In addition to that larger $\mathrm{Ca}^{2+}$ percentages were observed at the outer surface of the soaked specimens as a thin layer of calcium carbonate was precipitated on the surface.

(a)

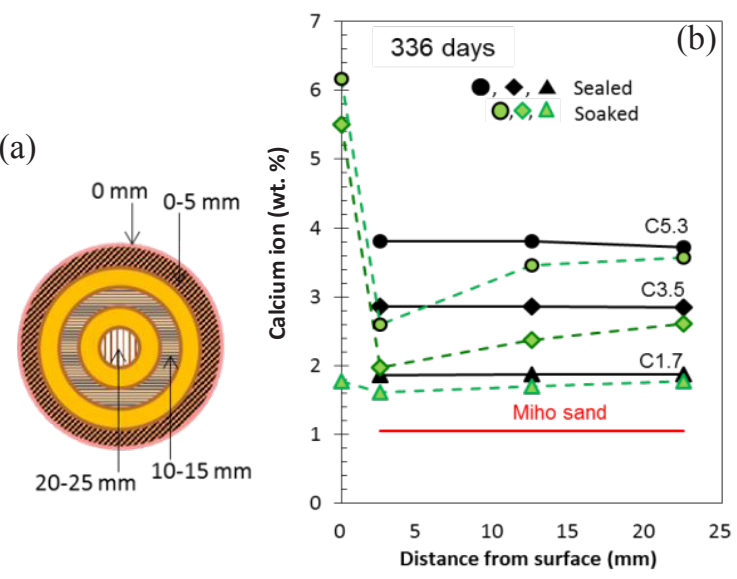

Fig. 6. (a) Schematic figure for distances (b) $\mathrm{Ca}^{2+}$ distribution within the specimen (XRF analysis)
To see the variation of $\mathrm{Ca}^{2+}$ content relative to sealed condition with a soaking period, Ca ratio between soaked and sealed specimens at particular depths were evaluated and plotted against the curing period for cement 1.7, 3.5 and $5.3 \%$ as shown in Fig. 7 (a), (b) and (c) respectively. Ca ratio of all specimens showed a value less than 1 in the distance of $0-5 \mathrm{~mm}$. In the case of cement 3.5 and $5.3 \%$, the $\mathrm{Ca}$ ratio at that distance was proportionally reduced while increasing the curing period by proving progression of calcium leaching out from the specimen.

When comparing the Ca ratio of cement 3.5 and $5.3 \%$ in the distances of 10-15 mm and 20-25 mm, it could be observed that larger ratio of $\mathrm{Ca}^{2+}$ has leached out from cement $3.5 \%$ specimen than from cement $5.3 \%$. The reason for this behaviour might be the difference in water permeability in both specimens. This will be confirmed by permeability test results in the future.
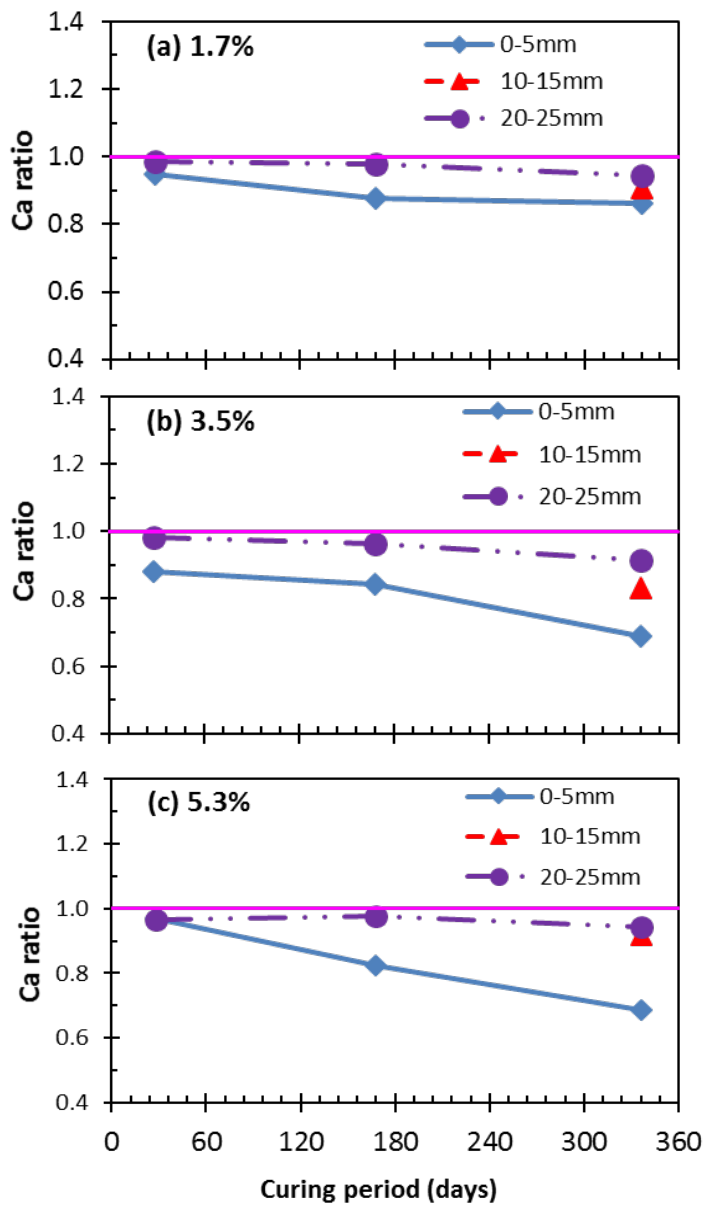

Fig. 7. Relationships between Ca ratio and the curing period

As a larger ratio of $\mathrm{Ca}$ has leached out from cement $3.5 \%$ specimens, EPMA was applied on the soaked specimens after curing of 28, 168, 336 days and a sealed specimen after 168 days curing. Fig. 8 shows the obtained $\mathrm{Ca}^{2+}$ distributions in the cross section for each of the specimen. By considering the colour distribution a clear difference could be observed in $\mathrm{Ca}^{2+}$ distributions between sealed and soaked specimens, especially after curing of 336 days. 

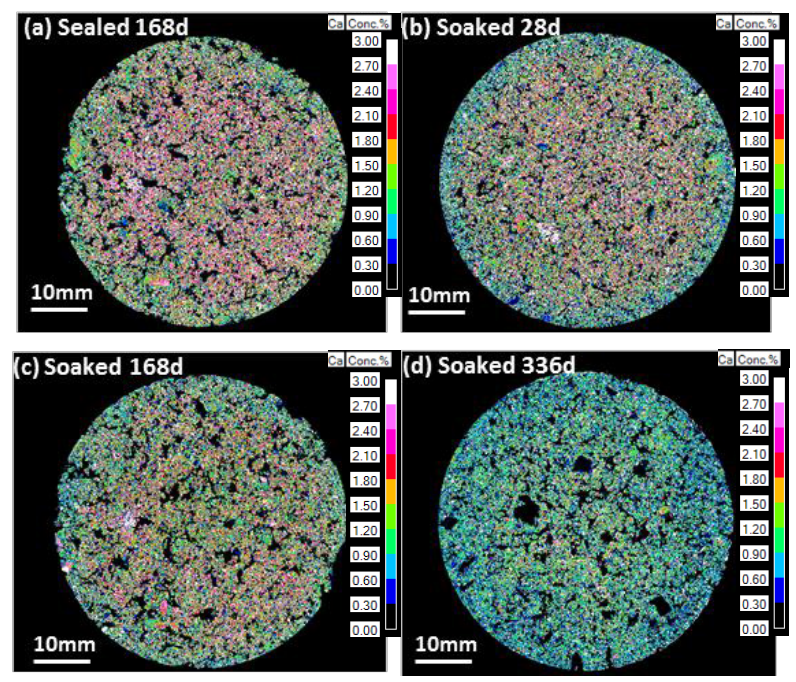

Fig. 8. Distribution of $\mathrm{Ca}^{2+}$ in the cross section of the specimens (EPMA-pixel size $35 \mu \mathrm{m}$ )

Fig. 9 shows the $\mathrm{Ca}^{2+}$ distribution profile of cement paste of each specimen. Here, profiles were named as $a, b$, $\mathrm{c}$ and $\mathrm{d}$ by referencing to the Fig.8. In the analysis, position and the size of the voids in each specimen were identified and eliminated using the EPMA results of carbon ion distribution as carbon was the main constitute in the epoxy resin. In the calculation, it was assumed all the voids were properly filled with epoxy resin and the carbon weight $\%$ of voids were decided as 15 or 30 according to the obtained results in resin. To distinguish the cement paste from the soil particles, the range for cement paste was selected as silica $<28$ weight $\%$, by considering silicon dioxide composition in Miho sand as in Table 2 [8]. After choosing the pixels only with cement paste, $\mathrm{Ca}^{2+}$ distribution was averaged radially from the centre to the surface using a MATLAB script. In the calculation, the number of pixels only with cement paste within a $5 \mathrm{~mm}$ radius was counted. Then the thickness of the next hollow circle was determined through iterations by keeping the initially counted number of data as a constant. Same procedure was followed up to the edge of the specimen.

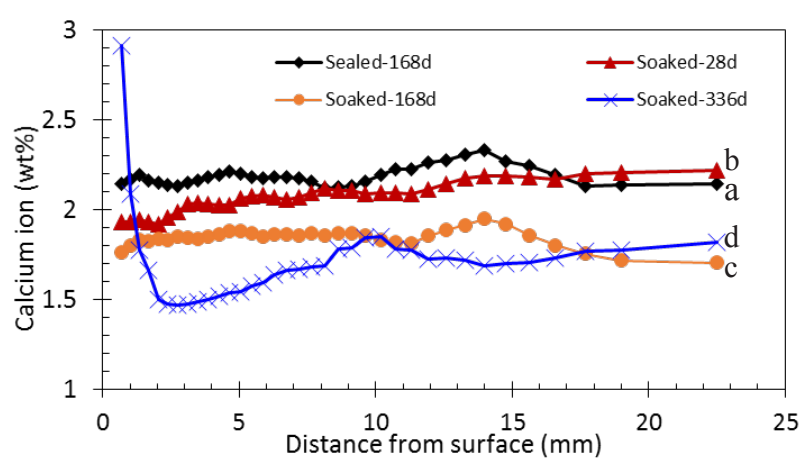

Fig. 9. $\mathrm{Ca}^{2+}$ distribution profiles

Under the sealed condition, the standard deviation of analysis results was 0.11 and 0.08 at distance of $0-5 \mathrm{~mm}$ and $20-25 \mathrm{~mm}$ respectively due to the variation in the microstructure. By considering that fact, a clear difference in $\mathrm{Ca}^{2+}$ contents between sealed and soaked specimens could be observed throughout the specimen after soaking of 168 and 336 days. Especially the smallest percentage of $\mathrm{Ca}^{2+}$ at the depth of $2 \mathrm{~mm}$ was observed in 336 days. On the other hand, it was expected to observe similar percentage of $\mathrm{Ca}^{2+}$ at the same depth in the profile $\mathrm{c}$ in 168 days to explain the "degraded depth" as stated in section 3.2. These results proved that it is difficult to explain the reason for localized strength reduction only with the remaining amount of localized calcium. In addition to that, a clear increment in $\mathrm{Ca}^{2+}$ at a depth less than $2 \mathrm{~mm}$ depth in profile $d$ could be observed due to the precipitation of calcium carbonated on the outer surface of the specimen similar to the observation in XRF analysis in Fig. 6(b). EPMA results also proved that leaching of calcium has progressed up to the centre of the cement $3.5 \%$ specimens while increasing the curing period.

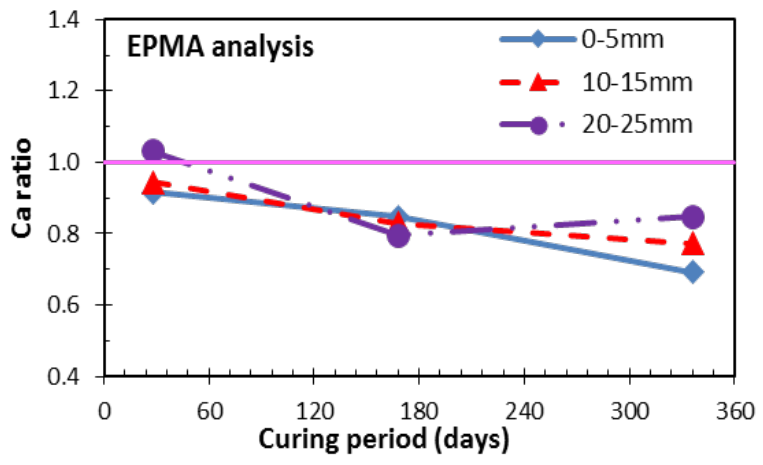

Fig. 10. Relationship between Ca ratio and curing period obtained by EPMA analysis

Ca ratio was evaluated using $\mathrm{Ca}^{2+}$ distribution obtained from EPMA analysis, and regenerated Fig.7 (b) as shown in Fig.10. It should be noted that Ca ratio in 336 days at depths of 0-5 $\mathrm{mm}$ was evaluated using the data at depths of $2-5 \mathrm{~mm}$ in the calculation. Here, $\mathrm{Ca}$ ratio of all specimens showed a value less than 1 in both distances of 0-5 $\mathrm{mm}$ and $10-15 \mathrm{~mm}$. Ca ratio only within $0-5 \mathrm{~mm}$ distance was proportionally reduced while increasing the curing age by following a similar trend of $\mathrm{Ca}$ ratio obtained by XRF results while the trend of 20-25 mm was different.

\subsection{Correlation between $\mathrm{Ca}$ ratio and penetration resistance ratio}

To find a relationship between $\mathrm{Ca}^{2+}$ distributions and the localized strengths, Figs. 11(a), (b) and (c) were prepared by plotting the penetration resistance ratios, $\mathrm{R}_{\mathrm{p}}^{1}$, against Ca ratios of 28, 168 and 336 days according to depths as of 0-5 mm, 10-15 mm and 20-25 mm, respectively. In the legend " $\mathrm{X}$ " and "E" was referred for the Ca ratios obtained from XRF analysis and EPMA analysis respectively. It should be noted that the penetration resistance ratios here are different from Fig. 5 as they were re-evaluated as an averaged value within the relevant distances as of $0-5,10-15$ and $20-25 \mathrm{~mm}$. The obtained $\mathrm{R}_{\mathrm{p}}^{1}$ in $0-5 \mathrm{~mm}$ depth were varying from 0.15 to 0.66 while the Ca ratio varying from 0.68 to 0.97 as in Fig. 11 (a) 


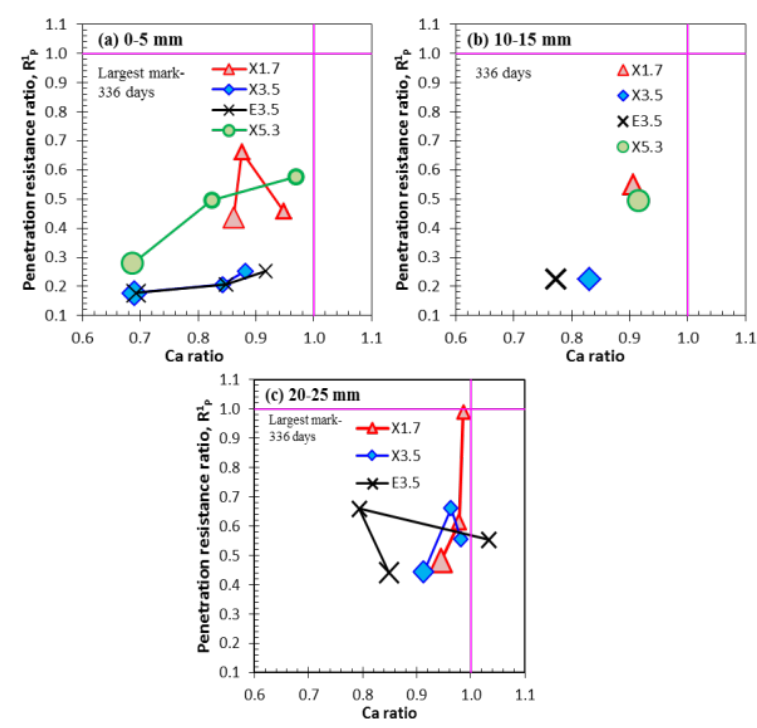

Fig. 11. Relationships between Ca ratios and penetration resistance ratios in different depths

while those values in Fig. 11(c) were from 0.4 to 1 and from 0.8 to 1.03 , respectively. A tendency of strength reduction due to leaching of calcium while increasing soaking period could be observed only within $0-5 \mathrm{~mm}$ distance in cement contents of 3.5 and $5.3 \%$. Nevertheless, it could not be able to find a correlation between Ca ratio and $\mathrm{R}_{\mathrm{p}}^{1}$ as it was varying in a large range at a particular Ca ratio.

It was not possible to come to a conclusion on the mechanism of the progression of deterioration of cement treated soil with low mixing ratios only by evaluating the remaining amount of $\mathrm{Ca}$. There might be several reasons for that where further investigations are required. One of the reasons might be the evaluation method of $\mathrm{R}_{\mathrm{p}}^{1}$. In this study, it was evaluated based only with three measurements. The number of measurements need to be increased in future to evaluate $\mathrm{R}_{\mathrm{p}}^{1}$ accurately as it depends on the microstructure of the improved soil where it is not always uniform. Another reason might be the state of the remaining $\mathrm{Ca}^{2+}$. In cement treated soil $\mathrm{Ca}^{2+}$ exists in three states as free, adsorbed and hydrates [9]. Free $\mathrm{Ca}^{2+}$ exist in pore water and adsorbed $\mathrm{Ca}^{2+}$ exist in soil particles where $\mathrm{Ca}^{2+}$ in both of those two states can be easily leached out than $\mathrm{Ca}^{2+}$ in hydrates such as ettringite or calcium silicate hydrate (C-S-H) [10]. In addition to that, different crystalline or non-crystalline substances also can be formed due to soaking [9]. Therefore, to clarify the existence and quantify the contribution of above stated chemical substances on the localized strengths, additional analysis will be conducted through X-ray diffraction (XRD) and thermo gravimetric analysis (TG/DTA) after applying heavy liquid method for powdered samples. Additionally, under same curing conditions, more specimens with larger curing period will be tested.

\section{Summary}

In this study, the progression of deterioration of cement treated surplus soils with lower mixing ratios was investigated under soaked condition by conducting needle penetration test and analysing remaining $\mathrm{Ca}^{2+}$ distribution by XRF and EPMA up to 336 days curing.

From needle penetration test results, it was found that the deterioration of cement treated soil occurred due to soaking and it depends on the soaking period. In all the cases deterioration had been progressed through out the specimen.

Both XRF and EPMA results proved that $\mathrm{Ca}^{2+}$ leached out from the centre to the surface of the specimens and it is being progressed with the soaking period. $\mathrm{Ca}^{2+}$ distribution obtained from both techniques did not follow a good correlation with localized strength distribution. It was understood that the progression of deterioration of improved surplus soils with lower cement contents cannot be explained only with the remaining amount of calcium.

This study was conducted as a collaborative research with Japan Cement Association, Japan Lime Association, The University of Tokyo, Fudo Tetra Corp., Fujita Corp., Hazama Ando Corp., Maeda Corp., Mikasa Sangyo Co. Ltd., Nishimatsu Construction Co. Ltd., Nishio Rent All Co. Ltd., Obayashi Corp., Sakai Heavy Industries, Ltd., and Public Works Research Institute. The authors gratefully acknowledge their assistance.

\section{References}

1. M. Kitazume, T. Nakamura, M. Terashi, K. Ohishi, Grouting and ground treatment, 586-597 (2003)

2. H. Hashimoto, T. Hayashi, H. Hayashi, $19^{\text {th }}$ Southeast Asian Geotechnical Conference, 361-366 (2016)

3. P. V. Ngoc, B. Turner, J. Huang, R.Kelly, $19^{\text {th }}$ Southeast Asian Geotechnical Conference (2016)

4. H. Takahashi, Y. Morikawa, N. Fujii, M. Kitazume, Proc. Inst. Civ. Eng. - Ground Improv., 171 (3), 135147 (2018)

5. Y. Miyashita, G. Inoue, Deep foundations and ground improvement, 1151-1159 (2018)

6. Y. Miyashita, D. Sanjeewani, R. Kuwano, ISGlasgow (2019) (to be published)

7. Japan Cement Association, Ground improvement manual using cement-based product (2012)

8. D. Mori, K.Yamada, Y. Hosokawa, M. Yamamoto, J. Adv. Concr. Technol., 4 (3), 369-383 (2006)

9. M. Kamon, C.Ying, T. Katsumi, Soils Found., 36 (4), 91-99 (1996)

10. K. Maekawa, T. Ishida, and T. Kishi, Multi-scale Modeling of Structural Concrete (2009) 